\title{
Limites e Possibilidades da Decisão em Matéria Ambiental $^{1}$
}

\author{
Limits and Possibilities of Decision in Environmental Matters
}

\author{
Jeferson Dytz Marin \\ Universidade de Caxias do Sul, Caxias do Sul - RS, Brasil \\ Mateus Lopes da Silva \\ Universidade de Caxias do Sul, Caxias do Sul - RS, Brasil
}

Resumo: A consecução regular dos preceitos propugnados na carta fundamental do Estado Democrático Socioambiental de Direito é árdua e trabalhosa, pois cada uma das práticas deve ser justificada e lastreada por um arcabouço normativo peculiar para que assim os personagens institucionais possam atuar de maneira segura e regular. Mas essa atuação acontece por meio de qual processo? Por intermédio da decisão. Dessa forma, procura-se dissertar sobre tal procedimento, evidenciando a maneira pela qual ela é erigida, retratando suas limitações e expondo as possibilidades que o seu uso proporciona à sociedade. Tal reflexão é construída tendo em vista a interação com as garantias constitucionais processuais que repercutem, tanto no meio judicial como no administrativo. Ao fundo, como marco essencial, contextualiza-se a discussão com a perspectiva ambiental.

Palavras-chave: Garantias Constitucionais. Decisão. Meio Ambiente.

1 Recebido em: 16/07/2013

Revisado em: 16/10/2013

Aprovado em: 18/10/2013
Abstract: The achieving of regular fundamental precepts instituted on the Constitucional Letter of the Democratic State Environmental Law is arduous and laborious, because each practice must be justified and backed by a peculiar normative framework so that the characters can act safely institutional. But this procedure happens through what process? Through the decision. Thus, this paper seeks to elaborate on this procedure, showing the manner in which it is erected, exposing its limitations and the possibilities that its use provides society. Such reflection is built in order to interact with the constitutional guarantees, which reflect both the judicial middle, as in administration. In the background, as touchstone, contextualizes this discussion with an environmental perspective.

Keywords: Constitutional Guarantees. Decision. Environment. 


\section{Introdução}

A decisão é elemento marcante para a atuação dos agentes públicos. Sem ela, não existe qualquer encaminhamento administrativo/institucional. Essa decisão, no decorrer da história, foi erigida sob diversos fundamentos, sendo que a partir da sua conformação formal causaram desencantamentos e iniquidades, porque verdade e falsidade tiveram de ser assimiladas pelo Direito. O emprego da decisão formal, tanto na seara jurídica como política, produziu decisões insensatas, por conseguinte inúteis à pragmática.

Assim, coube aos operadores do direito buscar uma solução possível para conformar a decisão à realidade pragmática, sem perder os freios e contrapesos propugnados pelo Direito. Tal feito foi alcançado pelo emprego da lógica do razoável produzindo uma decisão mais verossímil do que eminentemente certa. Destaca-se que as regras ou os princípios, assim como as decisões públicas formalmente processadas (precedentes), não possuem validez intrínseca, por isso devem ser interpretados e aplicados com esteio em valores, tais como: justiça, igualdade, liberdade e agora: equilíbrio ambiental. Para a promoção da proteção e defesa de diversos valores, dentre os quais o ambiental, as regras, princípios e precedentes jurídicos devem ser compreendidos como utensílios possíveis de serem utilizados para produzir o equilíbrio ecológico certificado na Constituição Federal, mas não como um remédio para todos os males.

Dessa forma, este trabalho investiga como a decisão é lapidada no universo jurídico, tendo por foco primordial a decisão sobre as questões ambientais. O problema, portanto, cinge-se ao exame dos limites e as possibilidades de tal procedimento, retratando peculiaridades que conformam consecução, como os freios constitucionais, a discricionariedade e as dificuldades de interpretação factual. Tal decisão não deve ser entendida apenas como aquela oriunda do procedimento judicial, mas também aquelas advindas do contexto administrativo, uma vez que o Estado atua tanto em nível judicial como administrativo.

O método utilizado para o desenvolvimento deste trabalho é o fenomenológico-hermenêutico, sendo que sua construção teórica está las- 
treada principalmente nas reflexões de Dworkin, Ovídio Baptista da Silva, Lenio Streck e na produção precedente de um dos coautores, Jeferson Dytz Marin.

No primeiro capítulo, estão expostas, de maneira ampla, as bases fundantes da decisão, de forma a contextualizar a necessária interação com as práticas do Estado brasileiro, vislumbrando, concomitantemente, a perspectiva da decisão em matéria ambiental; no capítulo seguinte, apresenta-se os limites da decisão, destacando que tais turbações encontram guarida nas contingências do decisor - aspectos culturais e de formação pessoal -, na capacidade material dos seres humanos - matriz de compreensão dos fatos - e nas garantias constitucionais que a fundamentam - princípios e procedimentos; ao final, são apontadas quais são as possibilidade da decisão no universo jurídico, esmiuçando pontos de interferência sobre o meio ambiente e a sociedade.

\section{A Decisão em Sentido Amplo e o Contexto Ambiental: reflexão jurídica e social}

Toda a decisão pública ambiental deve visar o restabelecimento do equilíbrio ecológico num nível saudável para o ambiente holístico. Nesse sentido, a lógica formal, que se propõe a explicar conexões entre ideias pelo emprego do método da inferência, não aborda os sentidos e os nexos entre as significações culturais, haja vista que a inferência não se presta para produzir conhecimento válido nas ciências não exatas, por isso ela é imprópria para a produção da decisão ambiental. É que as previsões abstratas previstas na lei não contêm plenitude de sentido antes de serem aplicadas na realidade da vida concreta. Por isso, a lógica necessária à defesa ambiental tem que considerar a finalidade do ato decisório inicial definido, qual seja: defesa ambiental. A lógica da decisão tem que ser sensível ao fim que se propõe, ou seja, tem que haver o mesmo sentido entre a lógica da decisão e a defesa ambiental buscada por ela. $\mathrm{O}$ direito se completará somente na ação administrativa realizada para a defesa ambiental em concreto e não na previsão abstrata. Nessa senda, o Direito é somente 
um instrumento que terá sentido quando da realização da decisão, pois não possui um fim em si mesmo.

A decisão pública ambiental não atuará no campo das evidências, mas onde existem inúmeros fatores a considerar e escalonamento de valores tidos como mais corretos de serem empregados. Deverá conter uma adequação histórica de modo a compatibilizar a solução com o momento histórico (contexto) presente e futuro onde a ação irá produzir resultado, de onde se retira as informações necessárias para aferir as condições reais de eficácia das escolhas contidas no mérito decisório. É que nada adianta uma decisão que crie uma norma para regular o caso concreto que não seja viável e praticável no momento de sua concretização. A decisão ecológica não pode ser ineficaz, nem criar mais ou outros problemas ecológicos.

Nesse sentido, a lógica do razoável e do verossímil permanece aberta ao mundo concreto, reconhecendo sua contingência e complexidade, por isso, contempla a necessidade da adequação entre ato e finalidade e se nutre não apenas da razão humana do decisor, mas também das experiências alheias dos participantes no processo.

As teorias da decisão mais adequadas à tutela ambiental administrativa são aquelas que romperam com a lógica clássica e, por isso, possibilitaram um pensamento jurídico pautado pela hermenêutica, que reconhece um espaço para o uso da discricionariedade, mas requer que a decisão pública seja legitimamente fundamentada. A partir disso, a decisão deverá permitir ser influenciada por interessados e pela realidade concreta do mundo do ser, permitindo se impregnar pelos valores políticos, sociais e todos aqueles permitidos pelo texto constitucional, sem jamais se deslocar do propósito e finalidade ecológica.

A República Federativa do Brasil constitui-se em Estado Democrático de Direito ${ }^{2}$ que exerce o poder do seu povo por meio das funções independentes e harmônicas entre si, quais sejam: o Legislativo, o Exe-

\footnotetext{
${ }^{2}$ Art. $1^{\circ}$ A República Federativa do Brasil, formada pela união indissolúvel dos Estados e Municípios e do Distrito Federal, constitui-se em Estado Democrático de Direito. (BRASIL, 1988)
} 
cutivo e o Judiciário ${ }^{3}$. Esse poder é exercido a partir do paradigma formal da igualdade perante a lei, que se dirige a todos sem distinção de qualquer natureza, tanto que "[...] ninguém será obrigado a fazer ou deixar de fazer alguma coisa senão em virtude de lei”. Nesse passo, a Constituição Federal impõe que a sua Administração Pública direta e indireta de qualquer dos Poderes da União, dos Estados, do Distrito Federal e dos Municípios obedecerá ao princípio da legalidade, entre outros.

A partir desses dispositivos constitucionais, a doutrina nacional passou a produzir um indevido pensamento jurídico legalista. Veja-se Di Pietro (2006, p. 82):

Segundo o princípio da legalidade, a Administração Pública só pode fazer o que a lei permite [...]. Em decorrência disso, a Administração Pública não pode, por simples ato administrativo, conceder direitos de qualquer espécie, criar obrigações ou impor vedações aos administrados; para tanto ela depende de lei.

Com o passar do tempo, os problemas de interesse público, produzidos pela sociedade pós-moderna, passaram a decorrer de causas cada vez mais complexas e remotas, demandando decisão e ação públicas mais bem elaboradas. Esses atos administrativos produziram um alargamento necessário da discricionariedade dos agentes públicos, haja vista demandarem maior conhecimento técnico-científico produzido por ciências não jurídicas. Tudo isso promoveu o aumento da possibilidade de escolhas e soluções válidas perante o Direito. Essa ascensão da discricionariedade frente aos casos concretos complexos força a redução e a relativização do núcleo essencial do princípio da legalidade frente à Administração Pública.

Ciente dessa nova realidade, o constituinte reformador por meio da Emenda Constitucional n. 19 introduziu expressamente na Carta Magna o dever do Estado permitir a participação direta da coletividade na Administração Pública direta e indireta. Veja-se o artigo 37, parágrafo $3^{\circ}$ “A lei disciplinará as formas de participação do usuário na administração pública direta e indireta". Essa participação necessária da coletividade está in-

${ }^{3}$ Art. $2^{\circ}$ São Poderes da União, independentes e harmônicos entre si, o Legislativo, o Executivo e o Judiciário. (BRASIL, 1988) 
timamente relacionada com a processualização do direito administrativo, especialmente com a exigência do devido processo constitucional democrático.

A realidade verificada no mundo do ser e verificada na Constituição Federal reconhece a crise da lei formal e passou a requerer um novo pensamento jurídico divorciado do pensamento jurídico liberal exegético atrelado a lógica formal cartesiana que visava reduzir a decisão e ação da Administração à reprodução exata da lei. A legalidade constitucional, $a$ justiça constitucional visa a promover o diálogo institucional entre os poderes, reservando ao poder legislativo a função primária de legislar para fixar diretrizes para as políticas setoriais, inclusive na seara ambiental. Esse pensamento jurídico que rompe com a justiça legal reconhece um espaço virtuoso para os poderes Executivo e Judiciário no desenvolvimento e na concretização do Estado Socioambiental.

Os problemas ambientais locais da sociedade brasileira contemporânea exigem do agente público o conhecimento técnico não jurídico na resolução dos novos desafios impostos à Administração Pública que vai além das previsões legais abstratas elaboradas a priori. Obviamente não se está a defender que seja dado um cheque em branco para o Estado-Administração, mas defendendo o reconhecimento da elevação da valorização do diálogo institucional entre os poderes com a coletividade.

O julgador tem o dever de prestar contas de sua decisão (accoutability). A jurisdição, assim, precisa ser controlada, como forma de asseguração da plenitude democrática. E esse controle, naturalmente, não deve vir por intermédio de embargos declaratórios, que acabaram por semear um certo consenso de que decisões "mal fundamentadas" existem e impõem a necessidade da convivência. A chancela materializa-se no reconhecimento da decisão como um "ato de responsabilidade política" do Juiz - como quer Dworkin. (MARIN, 2010, p. 24)

É fora de dúvida que a compreensão clássica da Administração Pública como bouche de la loi criada pela corrente de pensamento liberal, defendendo que a ela deva atuar da forma mais mecânica possível apli- 
cando as leis editadas pelo Poder Legislativo foi superada. O labor público reclama uma atitude hermenêutica do agente a cada dia mais.

Para romper com essa idéia de formalismo jurídico, é necessário reconhecer que o discurso jurídico está firmado em axiomas estabelecidos a partir dos conceitos admitidos como válidos, aceitando-se que a verdade obtenível é sempre relativa. Certamente que o pensamento dogmático é fruto da formação acadêmica dos juristas, porquanto tem como paradigma fundante a repetição sintomática que firma uma dependência epidêmica da lei, formando eternos alimentadores dessa vetusta prática alienada. Como afirma Ovídio Baptista: "A aceitabilidade racional', expressa pelo verossímil no pensamento clássico, deve tomar o lugar da racionalidade linear da epistemologia das ciências empíricas". (MARIN, 2010, p. 85)

Por tudo isso, a ação pública e o ato administrativo constitucionalmente adequado deve ser um ato de inteligência e não apenas um ato mecânico reprodutor de regulamentos fiéis à lei, ela deve ser ao mesmo tempo um produto da razão humana e da vontade soberana constitucional da Nação.

\section{Limites da Decisão}

Todas as decisões públicas trazem as marcas do agente decisor, suas defecções decorrentes da condição humana, haja vista que a perfeição não é humana, bem como traz a complexidade do objeto sobre o qual se decide. Assim qualquer decisão será marcada por ideologia e contingência. A certeza é de que a dúvida estará sempre presente, já que é decorrente das contingências naturais do mundo do ser. Tal assertiva pode ser exemplificada a partir da compreensão do problema da análise do problema ambiental que será objeto da decisão e determinará seu mérito. Imagine os lixões existentes nos municípios do Brasil: Qual é o problema? Será a contaminação do solo, o excesso de embalagens one way, ausência de logística reversa, o descarte irregular, a solidão do consumidor, seu sofrimento aplacado pelo prazer efêmero do consumo? 
A partir dessa constatação é necessário aclarar que toda decisão possuirá limites materiais próprios da capacidade de análise humana do problema a ser resolvido, entretanto, todo o processo decisório contido nos autos do processo administrativo municipal deverá relatar o método de análise e aproximação ao problema, seu exame e sua compreensão. $\mathrm{Na}$ seara administrativa ambiental, essa tarefa deverá ser realizada por equipes multidisciplinares formadas por agentes públicos e pela coletividade com conhecimento técnico-científico ou experiência na área do "problema". Nesse sentido, os ensinamentos de H.G. Gadamer são imprescindíveis para a compreensão de que o método empregado na produção de conhecimento científico sempre produzirá um conhecimento incompleto e limitado, por conseguinte, da mesma forma, jamais a decisão pública será capaz de produzir "a verdade".

Sempre parte da problemática estará encoberta, porque o conhecimento produzido restará limitado pelo método empregado. Também por essas razões, afirma-se que o pensamento positivista legalista pode beirar o irracional. Neste sentido é preciso visualizar o que de fundo (objeto) a burocracia tem em vista quando decide. Sempre haverá pontos do problema mal compreendidos ou mal descritos gerando limites ao mérito decisório, por conseguinte a categoria da verdade perde definitivamente espaço para a categoria do verossímil de Ovídio Baptista da Silva.

É indiscutível haver também na ciência do direito e na filosofia do direito critérios de verossimilhança, de evidenciação, de falsificação e, assim, uma base para uma argumentação "razoável" bem como para um "consenso intersubjetivo". Daí fazer sentido, afinal, falar, também aqui, de "conhecimentos" e de "ciência". É claro que, nestes domínios, não existe uma "racionalidade" no sentido de exatidão matemática. No entanto, isto não quer dizer que aí se proceda "irracionalmente". Uma investigação também não é irracional por se ocupar de fenômenos que, pela sua parte, não são inteiramente racionais. Assim, a hermenêutica jurídica é uma ciência plenamente racional, se bem que - não: precisamente porque não trata o processo de determinação do direito como uma pura conclusão lógico-formal, mas como um processo muito mais complexo, que também compreende momentos produtivos, dialéticos, porventura 
até intuitivos. Irracional é fechar os olhos perante estes momentos. Uma ciência não pode, naturalmente, colocar-se em confronto com a lógica. Mas uma ciência que não se ocupa apenas do formal, tem de ir para além da pura lógica formal. (KAUFMANN; HASSEMER, 2002, p. 98)

Hodiernamente, os múltiplos temas que compõem o mérito da decisão ambiental são crescentes, complexos e, a cada momento, mais sofísticados. A cada avanço da tecnologia, a compreensão dos problemas ambientais decorrentes se torna mais exigente e difícil. Todo esse ambiente de complexidade e de sofisticação epistemológica permite diversas e diferentes compreensões sobre as escolhas possivelmente certas, haja vista que o agente que decide interpreta o problema, o texto e o contexto onde decide. Tudo isso impõe a discricionariedade na decisão definitivamente. O mérito decisório decorre, assim, da ambivalência das escolhas ambientais possíveis, assim como dos conflitos de entendimento e da contradição de saberes envolvidos. O mérito decisório nasce da dúvida e do conflito. Sem conflito de ideias não há necessidade de decisão. $\mathrm{O}$ agente que decide está inserido, portanto, num ambiente onde coexistem várias opções, desejos e vontades igualmente válidas. A partir dessa complexidade, o agente que decide a matéria ambiental deve observar as particularidades do caso concreto e o contexto em que ele está inserido, bem como o contexto em que o mérito de sua decisão irá produzir consequências.

Decidir é um ato de inteligência e não um ato de repetição mecanizada de dogmas, regras ou decisões passadas.

A realidade aferida, considerando a problemática ambiental, exige uma nova forma de (re)pensar as decisões públicas. É preciso resgatar a tópica aristotélica como método possivelmente adequado de equacionar os novos problemas.

O pensar tópico como forma de argumentação diferencia-se da dogmática. Pois a dogmática parte de pontos de vista indiscutíveis e inegáveis, enquanto a tópica vale-se de pontos de vista abertos à discussão, já que são tentativas de compreensão e não uma certe- 
za absoluta. Assim, o próprio dogma é possível de ser questionado. (BITTAR; ALMEIDA, 2006, p. 407)

A decisão pública deve abolir dogmas e abeberar-se de pontos de vistas aceitáveis e pertinentes ao problema a ser solucionado. Impõe-se a (re)utilização dos raciocínios dialéticos, haja vista que na decisão pública ambiental local há mais de um problema coexistindo, quais sejam: a ideologia do decisor, a complexidade do objeto e a existência de mais de uma resposta certa. Nesse sentido, é necessário que a decisão parta de opiniões razoáveis e aceitas (e não de dogmas), ainda que conflitantes, a fim de chegar a uma decisão melhor trilhada pelo diálogo aberto e plural.

Para Aristóteles a dialética é simplesmente o procedimento racional não demonstrativo; dialético é o silogismo que, em vez de partir de premissas verdadeiras, parte de premissas prováveis, geralmente admitidas. Provável, diz Aristóteles, é o que parece aceitável a todos, à maioria ou aos sábios, e, entre estes, a todos, à maioria ou aos mais notáveis e ilustres. Por extensão, Aristóteles chama de dialético também o silogismo erístico, que parte de premissas que parecem prováveis, mas não são. (ABBAGNAMO, 2007, p. 271)

A partir desse método de trabalho é que deverão ser cotejadas as escolhas sugeridas no processo decisório pelos agentes públicos e coletividade, as quais determinarão o mérito da decisão. Nessa esteira, todos os envolvidos são responsáveis pela decisão pública final, por conseguinte é necessária uma fundamentação legítima a fim de demonstrar a justificação racional das escolhas havidas.

Se não podemos exigir que o governo chegue a respostas corretas sobre os direitos de seus cidadãos, podemos ao menos exigir que o tente. Podemos exigir que leve os direitos a sério, que siga uma teoria coerente sobre a natureza destes direitos. (DWORKIN, 2002, p. 286)

Durante as fases do processo, o conjunto de escolhas realizadas pelos agentes públicos é que determina o mérito da decisão. Disso evidencia-se que simples escolhas podem determinar o acerto da decisão fi- 
nal, assim toda a escolha é importante e importa em ato de inteligência e responsabilidade. Nesse sentido, todas as decisões ambientais municipais devem decorrer de parecer técnico amplamente discutido, porque uma escolha desavisada pode produzir enorme passivo ambiental, cite-se, por exemplo, a coerção estatal para realização de troca de sacolas de plástico por sacos de papel: qual delas gerará maior impacto? A responsabilidade pelas escolhas é que conduz a necessária fundamentação com a justificação racional dessas escolhas. Será arbitrária a decisão eivada de subjetividade injustificada, na qual argumentos vagos e inespecíficos procuram alimentar a exigência constitucional de fundamentação, afinal o sujeito que decide deve prestar conta de sua decisão.

Destarte, a decisão administrativa ambiental deve conter informações expressas que dêem conta da trajetória de formação da convicção do agente público. É imprescindível explicar a forma e o conteúdo das escolhas pela qual se tomou a decisão final. Esse é o dever constitucional de qualquer agente público que decide: fundamentar legitimamente sua decisão, explicando o problema e o motivo das escolhas que visam a sua solução e alcance da finalidade ecológica. A fundamentação deverá ser produzida de forma aderente ao fato concreto (problema ecológico) em linguagem inclusiva, distanciada de modelos decisórios apriorísticos editados para fundamentarem casos pretensamente iguais, o que provoca decisionismos e iniquidades.

É certo que outras decisões sempre serão possíveis porque a decisão decorre de um ato de interpretação e busca de sentido, razão pela qual o agente decisor deve refletir sobre todas as outras decisões possíveis aventadas, bem como justificar o conhecimento de suas consequências. O cotejamento (confronto) entre o conjunto de decisões possíveis para o mesmo caso concreto faz pressupor-se que a decisão finalmente escolhida seja a melhor para o caso concreto, considerando que a partir das discussões, realizadas pelos técnicos-científicos e pelos conselhos municipais ambientais, a preferência se dê pela decisão que contemplou melhor a complexidade do mérito e do ato de decidir. "Sem dúvida, um governo responsável deve estar pronto para justificar o que quer que faça, particularmente quando isso restringe a liberdade dos seus cidadãos". (DWORKIN, 2002, p. 293) 
Este é o momento de desfazer o equívoco de Dworkin ao identificar positivismo com arbítrio [...] a causa eficiente para o arbítrio, ao menos em nosso processo civil é a natureza declaratória da jurisdição, que dispensa os juízes de fundamentar as sentenças e os tribunais de fundamentarem seus acórdãos. Mas além da constatação indesmentível de que as sentenças arbitrárias são frutos da ausência de fundamentação [...]. (SILVA, 2009, p. 29)

Assim, percebe-se que a decisão formalmente acertada exige uma fundamentação legítima que consiste na justificação racional das escolhas possíveis havidas, sendo, além disso, um mergulho nas particularidades do caso concreto inserido num contexto histórico e físico a ser considerado. Jamais o agente decisor poderá justificar sua decisão na sua consciência.

De outra banda, a correção técnica do mérito decisório será determinada pelos critérios utilizados que implicaram nas escolhas contidas na decisão, em função das metas estabelecidas. Cite-se, por exemplo, segundo Campelo (2008), a baixa densidade de cobertura vegetal no município por habitante (menor do que $12 \mathrm{~m}^{2}$ por habitante). Esse problema ambiental apenas pode ser resolvido a partir de plantios de novas árvores no município. Assim, a aplicação do critério quantitativo e qualitativo demonstra a razoabilidade da decisão. Normalmente, os fundamentos científicos razoáveis satisfazem (limitadamente) a necessidade de correção técnica da decisão. O agente deve orientar sua decisão para a maximização das vantagens ecológicas possíveis e, provavelmente, esperadas. Essa aferição se dá a partir do emprego da razão prática que procura verificar se a decisão proposta é eficaz para atingir a meta estabelecida a posteriori, que é a proteção ambiental em nível satisfatório.

Diante da complexidade, é fundamental que todos os envolvidos no mérito decisório estejam sempre abertos a receber contribuições, a fim de melhor analisarem e examinarem os problemas ambientais. Isso possibilita que o poder público vislumbre as escolhas e as decisões alternativas, visando aperfeiçoamento das consequências e dos resultados reais. $\mathrm{O}$ foco deve ser centrado nas discussões como forma de participação democrática e republicana na decisão, que, ao ser fundamentada, revela-se não arbitrária e legitimada pela discussão plural. 
A lógica de se justificar a decisão simboliza a tentativa de torná-la aceitável, mediante a indicação dos problemas presentes e futuros, bem como das razões técnicas e jurídicas, ou seja, de que o agente aplicou os conhecimentos pertinentes em conformidade com o direito constitucional ambiental para solucionar os problemas detectados, a fim de concretizar a promessa constitucional integralmente. Essa justificação técnica e jurídica afasta a arbitrariedade e confere legitimidade material à decisão. Como as razões não possuem validez universal porque se vive num contexto plural e incerto, elas estarão suscetíveis à críticas e à possibilidade de aprimoramento e revisão constantes. O ideal é que o mérito decisório jamais fique preso às exigências cartesianas, mas também não caia na arbitrariedade. É preciso que ele seja um ato holístico de inteligência. A partir da fundamentação a decisão pode sofrer o controle interno do órgão e externo a ser realizado pela sociedade. Ela viabiliza o controle democrático do mérito técnico da decisão pública.

Percebe-se que o progresso do pensamento jurídico tornou o direito mais especializado, criando novos espaços de reflexão cada vez mais precisos como o Direito Ambiental, que, por sua crescente especialização, tornou seus contornos epistemológicos cada vez mais indeterminados. Isso se deve ao fato do constante aprimoramento de todas as outras ciências envolvidas com a questão ambiental, decorrentes do melhoramento tecnológico constante. As democracias têm criado contextos mais complexos e sofisticados culminando em acréscimos de exigências racionais para as decisões. Isso exige constante aperfeiçoamento das instituições decisoras, seja através da qualificação da burocracia, seja pela abertura a contribuições externas de cidadãos interessados.

\section{Possibilidades da Decisão}

A nova ordem constitucional permitiu a emancipação do raciocínio jurídico, fulminando a lógica reducionista imposta pelo positivismo. Toda a atividade pública deve elaborar normas jurídicas fundamentadas capazes de resolver os problemas concretos e não apenas conformes ao direito legal. A decisão tem que estar relacionada com a solução do problema 
público, por isso, ela decorre de um processo participativo. A decisão pública é um processo racional que ocorre num processo constitucional, por conseguinte não é um ato de outorga para execução. A decisão traz conteúdo moral e ético porque o agente que decide não é neutro ou desideologizado, por isso, o raciocínio técnico-científico e jurídico que produz a decisão administrativa ambiental não obedece à mecânica do raciocínio exato pautado pela lógica formal dedutiva. A decisão apropriada para construir o município socioambiental não nasce da dedução como pregava o racionalismo clássico.

O raciocínio jurídico deve partir do texto e ser engajado no contexto em que o problema ocorre, recebendo toda a contribuição dos tinos humanos calcados nas experiências, nos valores e nos argumentos plausíveis. $\mathrm{O}$ raciocínio jurídico apropriado para o estado ambiental deve harmonizar a justiça dada pelo Direito estatal e pelo Direito produzido fora da atividade estatal legiferante. A atividade do Estado-Administração deve aproximar a teoria produzida na academia da prática vivida nas secretarias municipais. A decisão ambiental necessária será sustentada pela categoria do verossímil, do razoável e do equitativo. Essa nova compreensão aposta na lógica não formal comprometida com a justiça pensada a partir do concreto em direção à lei e não da lei para o caso concreto.

Tentar subsumir o problema novo à previsão normativa velha produzirá inefetividade cada vez maior. Os problemas reais requerem formulação de decisões ambientais públicas reais, que transpassam os limites da concepção positivista do Direito. Nessa quadra é preciso admitir que o ponto de referência para a decisão não é a norma elaborada a priori, mas o fato/problema ambiental que causa a ação pública que produz o efeito solução. O problema público ambiental é a causa e o motivo da decisão e não a previsão hipotética.

A posição das partes não pode condicionar a decisão, mas deve ser considerada, influenciá-la, compor o arquétipo de argumentos que a forjará. Hoje, infelizmente, ela tem sido vista de soslaio. É preciso mudar essa realidade. Todos os operadores do direito devem participar da construção da justiça no caso concreto. O julgador não pode se colocar imune às partes e, alicerçado num convencimento 
pré-concebido, fruto de um verbete ou uma convicção oriunda da "própria consciência" olvidar as provas e os fatos debatidos no processo. É preciso combater o ativismo do juiz, pois arbitrário, mas valorizar o protagonismo do direito. A democracia também está representada no controle da decisão judicial. E essa tarefa cabe à sociedade e à lei. (MARIN, 2012, p. 437)

A fim de superar a crise ambiental é necessário pensar os fatos e as decisões fora da lei, acessando conhecimentos a partir de argumentos razoáveis, que possam gerar os efeitos dinâmicos e, ecologicamente, pertinentes e esperados. As premissas, científicas ou normativas, não podem ser encaradas como sistemas rígidos de opções, mas como modelos de possibilidades decisórias (standards). Com tal entendimento, a lei passa a trazer importante contribuição na medida em que auxilia o agente público a vê-la como um modelo de conduta, sem retirar sua liberdade de interpretação diante do caso concreto que reclama uma nova e dinâmica solução.

Em uma democracia, ou pelo menos em uma democracia que em princípio respeita os direitos individuais, todo cidadão tem um dever moral geral de obedecer todas as leis, mesmo que ele queira que algumas delas sejam modificadas. Ele tem este dever para com seus concidadãos que, para seu benefício, acatam leis de que não gostam. Mas este dever geral não pode ser um dever absoluto, porque mesmo uma sociedade em princípio justa pode produzir leis e políticas injustas, e um homem tem outros deveres além daqueles para com o Estado [...] as pessoas têm o dever de obedecer à lei, mas têm também o direito de seguir sua consciência sempre que esta entrar em conflito com tal dever [...]. (DWORKIN, 2010, p. 287)

Como somente a evidência torna desnecessária a argumentação e o debate, pode-se afirmar que a imensa maioria das decisões jurídicas será controversa, haja vista que os contextos e os problemas reais são dinâmicos e os participantes no processo decisório possuem racionalidades e aderem a morais plurais. 
Uma decisão da Suprema Corte continua sendo uma decisão jurídica e deve levar em conta os precedentes e as considerações institucionais, como as relações entre a Corte e o Congresso, assim como a moralidade. E nenhuma decisão jurídica é necessariamente a decisão correta. Os juízes representam diferentes posições quanto a questões controversas de direito e da moral [...]. (DWORKIN, 2010, p. 287)

Nesse contexto se avulta a ética e a responsabilidade ecológica na argumentação, limitada apenas pelas evidências ou imposições arbitrárias, mas não limitadas por comandos normativos ou precedentes, assim impõe-se o intenso responsável debate democrático sobre o mérito da decisão, mesmo havendo previsão normativa e precedentes semelhantes.

Para decidir corretamente, o decisor precisa interpretar a realidade. Precisa interpretar o Direito existente, o caso concreto, o meio e os membros que sofrerão os efeitos da decisão. Decidir pressupõe interpretar. $\mathrm{O}$ decisor precisa interpretar os fatos históricos precedentes, buscando compreender a sociedade e sua orientação (desejos, motivações, ideologias, racionalidades), suas atuações e problemas resultantes (considerar o contexto real percebido), bem como a função de sua decisão.

Dworkin supõe que as regras jurídicas existem em razão de algum interesse, propósito, valor ou finalidade. No caso do Estado brasileiro as regras do Estado existem para dar fiel cumprimento aos objetivos e finalidades contidos na Constituição Federal. Ocorre que as finalidades lá escritas são independentes das regras. As regras infraconstitucionais servem às finalidades constitucionais e não o contrário. Assim, pode ser que uma regra não atenda àquela finalidade num dado momento histórico, carecendo que a interpretação lhe dê o sentido necessário alcance daquela finalidade. As regras seriam instrumentos para a realização da finalidade, conforme Dworkin (2010, p. 57). Diante da declaração do direito ecológico fundamental, nenhuma lei pode ser interpretada de forma a provocar mais desequilíbrio ecológico ou degradação.

Dessa forma, o que legitima a decisão que pretende realizar a proteção ambiental não são as regras, mas o propósito de concretizar um ambiente ecologicamente equilibrado. Como a finalidade de equilíbrio eco- 
lógico independe das regras, o agente público decisor pode até mesmo abandonar as regras jurídicas, desde que tome a defesa ambiental como critério de validade da sua decisão. Sendo assim, o decisor atribui um valor moral à tutela ambiental a partir de suas convicções de moralidade política. As convicções do intérprete exercem um papel indispensável. Para Dworkin, interpretar não é apenas descobrir por que a tutela ambiental existe, mas o que ela devidamente compreendida requer.

Nesse sentido, por vezes, a tutela ambiental em nível ecológico adequado exigirá da Administração Pública uma ação que vai além das condutas já padronizadas.

Está, portanto, na interpretação a busca da democracia e não na universalização, amparada na conceitualização unívoca. Seu intento tem sido retirar o caráter fático e a personalidade das demandas, dando azo à evolução da tecnificação do direito, fundada na massificação, num lúgubre processo de produção seriática do que não pode ser (re) produzido. (MARIN, 2010, p. 22)

O processo interpretativo, proposto por Dworkin (2007, p. 81), que deve ser empregado nas decisões administrativas ambientais pode ser compreendido como tendo uma fase pré-interpretativa na qual são identificadas as regras e padrões que se consideram fornecer o conteúdo experimental da prática. Nessa etapa, o agente decisor deve precisar no que consiste a defesa ambiental que lhe é atribuída, como ela se apresenta, onde pode ser encontrada, quais regras prescreve, quais comportamentos exige. É o momento em que o objeto da interpretação é delimitado.

$\mathrm{Na}$ fase interpretativa, o agente decisor se concentra numa justificativa geral para os principais elementos da prática identificada na etapa pré-interpretativa. Nesse caso, oferecer uma justificação é demonstrar a conveniência da decisão, mostrando o propósito do ato que se deve executar. Tal etapa é justificativa porque nela o decisor demonstra quais as vantagens e acertos da prática a ser seguida e o que ela efetivamente exige. A conveniência da decisão administrativa municipal ambiental, v.g. poderá ser verificada a partir da constatação de que aquela decisão ambiental promove a defesa ambiental ao mesmo tempo em que promove, 
ou não aniquila outros direitos dos munícipes, como desenvolvimento econômico, saúde, lazer e serviços urbanos gerais, entre outros. A variável ambiental deverá estar presente em todas as decisões dos demais órgãos municipais, assim como as variáveis daqueles órgãos presentes na decisão ambiental. Isso deve ser demonstrado ou demonstrável.

A etapa final é pós-interpretativa porque o decisor formula um comando para que ele aconteça na prática de acordo com a justificativa apresentada na decisão, de maneira que o ato concreto se ajuste ao seu fundamento. Os fundamentos que são compatíveis com poucos aspectos da prática são inadequados. Asseverou Dworkin (2007, p. 306) que

Qualquer juiz desenvolverá, ao longo de sua formação e experiência, uma concepção funcional bastante individualizada do direito, na qual ele se baseará, talvez inconscientemente, para chegar a essas diferentes decisões e avaliações, e estas serão para ele, uma questão de sentimento ou instinto, e não de análise.

Como a interpretação é construtiva, o decisor atribui à prática suas convicções políticas e morais.

Dworkin propõe uma interpretação do direito como se faz a interpretação literária. Ela é um modelo para a interpretação do direito. A interpretação tenta mostrar que a maneira de ler o texto revela-o como a melhor obra de arte. Nesse sentido, a interpretação do direito é um processo construtivo, com isso não se quer afirmar que o agente decisor possa modificar o direito objeto da interpretação, haja vista que o próprio texto impõe limites ao decisor, haja vista que todas as palavras devem ser consideradas e não apenas tiras do texto. O texto deve ser interpretado em sua totalidade. Mas

[...] um cidadão pode seguir sua própria interpretação da lei mesmo julgando que os tribunais vão provavelmente se posicionar contra ele, não há nenhuma razão plausível para que ele aja de modo diferente, apenas porque uma decisão contrária já consta dos textos legais. (DWORKIN, 2007, p. 306) 
Quando o decisor estiver diante de um caso difícil, ou absolutamente novo, ele poderá recorrer aos casos precedentes e interpretar as decisões anteriores. Nessa interpretação, o decisor compreende os valores políticos e os motivos das decisões anteriores, trazendo-os como um modelo possível de decidir de acordo com a tradição e com a finalidade que pretende concretizar e alcançar com sua decisão.

Ao decidir o novo caso, cada juiz deve considerar-se como parceiro de um complexo empreendimento em cadeia, do qual essas inúmeras decisões, estruturas, convenções e práticas são a história; é seu trabalho continuar essa história no futuro por meio do que ele faz agora. Ele deve interpretar o que aconteceu antes porque tem a responsabilidade de levar adiante a incumbência que tem em mãos e não partir em nenhuma nova direção. Portanto, deve determinar, segundo seu próprio julgamento, o motivo das decisões anteriores, qual realmente é, tomando como um todo, o propósito ou o tema da prática até então. (DWORKIN, 2005, p. 328)

Quando o direito não demonstrar claramente qual é a decisão mais correta, o decisor deverá buscar nos princípios a resposta mais adequada para atingir o resultado pretendido pelo pacto realizado na Constituição Federal. Consoante Ronald Dworkin, o decisor deverá tentar identificar algum paradigma do direito para captar o que foi o direito em casos semelhantes já analisados. Após conhecer esse direito factual (positivado na história), o decisor deve interpretá-lo de acordo com os seus valores morais, a fim de captar qual propósito, princípio ou valor moral ele serviu. Para Dworkin, essa decisão não é arbitrária porque, embora o decisor imponha seus valores morais, ele oferece uma justificativa que se ajusta, mais ou menos, com o que o direito efetivamente foi e é no momento da elaboração da decisão.

Como já referi em outras oportunidades, os textos são fatos. Isto porque os textos são o dito de uma compreensão que se deu, necessariamente, como aplicação. Na verdade, temos que encontrar o fio condutor da tradição que se liga ao enunciado. Teremos que buscar - sempre, em face dos princípios da integridade e da coerência, que na hermenêutica denominamos de tradição - os casos e o contex- 
to em que esse enunciado foi produzido. Não é possível, portanto, continuarmos analisando os textos das súmulas como se ali fosse "o lugar da verdade" e como se o sentido imanente desse texto nos desse as respostas para a sua futura aplicação. (STRECK, 2009, p. 316)

A adequação da nova decisão ao direito depende de sua coerência com a história jurídica aferida no exame factual do direito de um passado breve, permitindo que a nova decisão continue a mesma história jurídica aderente ao passado jurídico e adequado ao resultado jurídico futuro pretendido. Então, o decisor não estando totalmente adstrito ao direito historicamente já produzido (positivado), possui discricionariedade para trazer seus valores morais, e agindo assim se utiliza de método interpretativo, que é um critério para decidir. Isso pode ser verificado na alegoria dos romancistas proposto por Ronald Dworkin.

Essa tentativa de compatibilizar o passado com o futuro na produção do direito pela decisão administrativa confere alguma estabilidade ao direito produzido pelas instituições públicas ambientais e demonstra a renovação (RAWLS, 1993) diária da adesão ao pacto deliberativo inicial que é a constituição federal passada e presente. Com isso fica demonstrado o compromisso com os pactos passados e com a realização dos pactos futuros.

Transferindo-se tais premissas aos órgãos públicos ambientais municipais, é possível afirmar que a burocracia deve decidir seus casos novos considerando os conhecimentos, regras e princípios científicos e jurídicos já positivados, mas utilizando de sua discricionariedade para imprimir os valores morais esperados da instituição que fazem parte naquele momento histórico; ou seja, os órgãos ambientais somente podem produzir decisões ambientais moralmente ecológicas considerando o estado das coisas, sob pena de perderem a coerência histórica com o passado e com o fim público que lhe são a razão de existir no presente.

Lacunas no ordenamento jurídico positivado sempre existirão porque o legislador não é onipotente e porque a realidade dos problemas concretos se mostra sempre dinâmica. Tais lacunas deverão ser preenchidas com o oferecimento de decisões fundamentadas legitimamente que 
encontram aderência no conhecimento positivado e nos resultados moralmente válidos perseguidos, quais sejam: promoção do equilíbrio ecológico e realização integral dos direitos fundamentais previstos na Constituição Federal.

O agente decisor está limitado pelos conhecimentos positivados que lhe serviram de ponto de partida, bem como com a moralidade institucional aceita e conhecida por todos porque materializada na Constituição Federal. Decidindo assim, o agente rompe com o paradigma do positivismo legalista na medida em que não age de acordo com uma lógica dedutiva que apenas declara, descreve ou explica o direito posto; bem como não produz uma decisão arbitrária de acordo com suas convicções morais pessoais, o que configura uma arbitrariedade decorrente do subjetivismo exacerbado. Assim, podem ser aceitas como válidas todas as decisões que não reproduzam o texto legal ou decisões já exaradas; e, ao mesmo tempo, que contemplem direitos políticos e morais sem que isso seja caracterizado como arbitrariedade e que ao final se harmonizem com as promessas contidas na Constituição Federal. "Faz parte da tarefa do governo 'definir' direitos morais através de leis e decisões judiciais, ou seja, declarar de forma oficial em que medida a lei incorporará os direitos morais". (DWORKIN, 2010, p. 303)

O agente público que decide é livre para interpretar o direito positivado, porém, ele deve ajustar sua decisão à história jurídica do país. Não fosse assim, o decisor não produziria um significado ao direito para resolver o novo caso concreto, haja vista que o direito a ser produzido na decisão já seria um fato que já existe no mundo do ser, devendo apenas ser aplicado por um autômato. Dessa forma, a resposta possível não decorre da mera racionalização subjetiva do agente que decide, nem é uma fórmula que existe e pode ser aplicada como solução. A solução depende da interpretação do agente, por isso, a decisão é um ato de inteligência.

É preciso superar a concepção de que cabe ao julgador a aplicação da norma e a adequação livre ao caso concreto, olvidando os parâmetros de interpretação e, no mais das vezes, dando azo ao velho critério subsuntivo, em franco ultraje à Constituição. Comum ainda decisões que, amparadas no "modismo" constitucional principioló- 
gico, buscam nele o injustificado amparo para razões pessoais, "da própria consciência". Não é dado a ele - julgador - decidir. O que há é uma transferência de uma atividade típica de Estado - o ato decisional - cujo chamado é atendido no momento da tomada de decisão. A ideia de Liebman, de que a sentença é um "ato de inteligência", sugerindo liberdade ao julgador, ou a de Chiovenda, que propõe ser a característica formal da sentença a exposição precisa do estado da questão resolvida e do trabalho mental realizado pelo juiz, precisam ser superadas. (MARIN, 2010, p. 466)

O modelo interpretativo de Ronald Dworkin defende que os textos positivados exercem uma limitação externa a qualquer decisão que decorra de normas, já que isso afasta o subjetivismo puro do agente que decide. Ao mesmo tempo, defende que a possibilidade de interpretação destes textos abre espaço para que o decisor faça escolhas de acordo com suas convicções políticas, éticas e morais, o que afasta o pensamento jurídico clássico pautado na descrição objetiva das decisões elaboradas a priori.

Os dois tipos principais de convicções que estão ao alcance de todo intérprete - sobre a interpretação que se adapta melhor ou pior ao um texto, e sobre qual das duas torna o romance substancialmente melhor - são inerentes a seu sistema geral de crenças e atitudes; nenhum tipo é independente desse sistema de alguma maneira que o outro não o seja. Essa observação convida à seguinte objeção: Se um intérprete deve, finalmente, basear-se naquilo que lhe parece certo, tanto ao decidir se alguma interpretação é apropriada quanto ao decidir se ela torna o romance mais atraente, na verdade não está sujeito a nenhuma coerção, pois nenhuma opinião pode ser constrangida, a não ser por fatos externos e irredutíveis com os quais todos devem estar de acordo. (DWORKIN, 2007, p. 282)

Não havendo possibilidade de coerção externa forte, é possível afirmar que é a fundamentação das escolhas que alcança liberdade para a (quase qualquer) interpretação sobre o que é o direito; na medida em que a fundamentação da nova decisão pode apontar erros no direito pretérito, justificando a decisão presente como melhor e diferente. A fundamentação demonstra que o decisor não inventa um novo direito, mas interpreta 
o passado e cria o presente de acordo com as novas necessidades trazidas pelo fato concreto, novo objeto da nova decisão.

Ronald Dworkin propõe um meio termo entre o subjetivismo sem limites e o objetivismo sem inteligência do julgador, afirmando que o direito é um conceito interpretativo que não se resume às normas prescritas pelo Estado, nem naquilo que o Estado declara ser o direito num dado momento; assim como não se resume ao mundo do jurídico, porque o direito está em todo o conhecimento reclamado pelo fato concreto, conhecimento que pode estar em qualquer ramo científico. $\mathrm{O}$ agente que decide e as instituições públicas não são isolados, mas imersos numa história jurídica impregnada por valores morais que merecem ser considerados em qualquer decisão.

A teoria da decisão judicial de Hércules não configura, em momento algum, nenhuma escolha entre suas próprias convicções políticas e aquelas que ele considera como as convicções políticas do conjunto da comunidade. Ao contrário, sua teoria identifica uma concepção particular de moralidade comunitária como um fator decisivo para os problemas jurídicos; essa concepção sustenta que a moralidade comunitária é a moralidade política que as leis e as instituições da comunidade pressupõem. Ele deve, por certo, basear-se em seu próprio juízo para determinar que princípios de moralidade são estes, mas essa forma de apoio é a segunda daqueles que distinguimos, uma forma que é inevitável em algum nível. (DWORKIN, 2010, p. 196)

Por isso, a decisão razoável válida depende de um ajuste com o direito positivado e também com a moral intersubjetiva em que a decisão produzirá efeitos, os atos decisórios devem ser consonantes com o direito positivo, assim como deve ser respeitada a moral institucional razoavelmente aceita pela sociedade, como um processo intersubjetivo de justificação da escolha. 


\section{Conclusão}

A produção da decisão deve ser vista como atividade de servidor que atua nesta qualidade desenvolvendo suas atribuições num Estado de Direito Socioambiental, ou seja, a decisão é, ao mesmo tempo, produto da razão humana e vontade soberana constitucional de um Estado. Logo, a decisão não será legítima apenas porque o Estado está no exercício da atribuição, mas porque ela é materialmente razoável na medida em que aplica o conteúdo democraticamente debatido e realizador da Constituição Federal e de outros conhecimentos técnico-científicos pertinentes ao caso concreto e capazes de realizar a promessa socioambiental.

Nessa linha, embora seja percebida a amplitude da decisão, em especial aquela colimada à seara ambiental, toda teoria da decisão deve ser limitada pelo respeito às garantias constitucionais e direitos fundamentais constitucionais, ou seja, deverá promover formal e materialmente a justiça constitucional. Diante da complexidade e da velocidade na qual o meio em que a decisão produzirá efeitos se modifica é fundamental que o decisor oficie como um hermeneuta, promovendo decisões decorrentes da reflexão não como mero autômato. Tem como limite o dever de detalhar o problema objeto da decisão, bem como promover intenso debate sobre escolhas que comporão o mérito decisório, prestando contas, ao final, sobre o que se decidiu.

Não havendo norma pronta a ser aplicada a casos futuros, ressalta-se a importância dos interessados influenciarem na decisão pública. $\mathrm{O}$ agente público, quando entra em contato com o discurso e as provas constantes nos autos do processo administrativo ambiental, recebe influência externa e pondera sobre as possibilidades, não como um autômato, mas como um agente que raciocina sobre as evidências demonstradas pela argumentação e depende do debate sobre o que foi carreado aos autos. A qualidade do debate determina a qualidade da decisão. Por isso, o ato de decidir é uma atividade criativa e complementar ao conhecido, por conseguinte, o processo decisório é um sistema autorreferente em que seus atos estão envolvidos consigo mesmo, devendo permanecer aberto a todos os conhecimentos pertinentes. 
Por tudo isso, como o juiz Hércules de Dworkin, que leva em consideração as tradições morais da sua comunidade, os agentes públicos também deverão estar atentos a aspectos transcendentes à legalidade quando da consecução de qualquer decisão, devendo conformar tal perspectiva com as garantias constitucionais, sem se esquecer de que o fruto desse ato repercutirá sobre o corpo social e o meio ambiente. Assim, embora complexa, cabe a cada agente público, e mesmo ao cidadão, harmonizar todas essas peculiaridades para decidir além dos formalismos, provocando uma repercussão material/concreta em face daquilo que avalia, especialmente quando cuidar do bem ambiental, que tem natureza intergeracional.

\section{Referências}

ABBAGNAMO, Nicola. Dicionário de filosofia. São Paulo: Martins Fontes, 2007.

BITTAR, Eduardo; ALMEIDA, Guilherme Assis de. Curso de filosofia do direito. 4. ed. São Paulo: Atlas, 2006.

BRASIL. Constituição de 1988. Constituição da República Federativa do Brasil. Brasília, DF, Senado, 1988.

CAMPELO, Célio da Cunha. Áreas verdes. [2012]. Disponível em: $<$ http://www.mp.sp.gov.br/portal/page/portal/cao_urbanismo_e_meio_ ambiente/material_apoio $>$. Acesso em: 5 ago. 2012.

DI PIETRO, Maria Sylvia Zanella. Direito administrativo. 19. ed. São Paulo: Atlas, 2006.

DWORKIN, Ronald. Levando os direitos a sério. São Paulo: Martins Fontes, 2010.

. Levando os direitos a sério. Traduzido por Nelson Boeira. São Paulo: Martins Fontes, 2002.

. O Império do direito. São Paulo: Martins Fontes, 2007.

. Uma questão de princípio. São Paulo: Martins Fontes, 2005. 
KAUFMANN, Arthur; HASSEMER, Winfried (Org.). Introdução à filosofia do direito e à teoria do direito contemporâneo. Traduzido por Marcos Keel e Manuel Seca de Oliveira. Lisboa: Calouste Gulbenkian, 2002.

MARIN, Jeferson Dytz. A Influência da universalização conceitual na efetividade da jurisdição: teorias da decidibilidade, (des) coisificação do caso julgado e estandartização do direito. São Leopoldo: Unisinos, 2010. Disponível em: $<$ http://bdtd.unisinos.br/tde_arquivos/11/TDE2011-0316T102302Z1348/Publico/JefersonMarinDireito.pdf > . Acesso em: 5 jul. 2012.

RAWLS, John. Uma teoria da justiça. São Paulo: Martins Fontes, 1993. SILVA, Ovídio Araújo Baptista da. Epistemologia das ciências culturais. Porto Alegre: Verbo Jurídico, 2009.

STRECK, Lenio Luiz. Súmulas vinculantes em Terrae Brasilis: necessitamos de uma teoria para a elaboração de precedentes? Revista Brasileira de Ciências Criminais, São Paulo: Revista dos Tribunais, v. 78, ano 17, maio-jun, 2009.

Jeferson Dytz Marin é Professor do Programa de Mestrado em Direito da UCSBRA. Doutor em Direito - UNISINOS-BRA. Mestre em Direito - UNISC-BRA. Advogado. Pesquisador CNPQ da UCS. Autor dos livros "Jurisdição e Processo: efetividade e realização das pretensões materiais Juruá (2008)", "Jurisdição e Processo II: racionalismo, ordinarização e reformas processuais (Juruá, 2009)”, "Jurisdição e Processo III: estudos em homenagem ao Prof. Ovídio Baptista da Silva (2009)", dentre outros. Coordenador do Grupo de Pesquisa ALFAJUS. Membro do IEM - Instituto de Estudos Municipais. E-mail: jdmarin@ucs.br. Endereço profissional: Rua 13 de Maio, 581, sala 402, Centro, Bento Gonçalves, RS, CEP: 95700-000. 
Mateus Lopes da Silva é Professor da Universidade Federal de Pelotas (RS) UFPEL/RS. Mestre em Direito pela Universidade de Caxias do Sul - UCS/RS, seguindo a linha de pesquisa: "direito ambiental e novos direitos". Membro regular do Grupo de Pesquisa ALFAJUS. Advogado.E-mail: srmateus@bol.com.br. Endereço profissional: Rua Gomes Carneiro, n. 1, Centro, Pelotas, RS. Caixa Postal 354. CEP: 96010-610. 